\title{
Finance transformation for healthcare: A structured model for planning and action
}

Harold Tan, Lim Yee Juan

National Healthcare Group, Singapore

Received: January 30, 2019

DOI: $10.5430 /$ ijh.v5n $1 \mathrm{p} 42$
Accepted: April 14, 2019

Online Published: April 18, 2019

URL: https://doi.org/10.5430/ijh.v5n1p42

\begin{abstract}
With rising healthcare costs, payers are transforming the way they pay healthcare providers. Currently, there is much interest in value-based financing and accountable care models. However, finance transformation in healthcare goes beyond changing funding models. The way funds flow to providers and how patients share healthcare costs also need to be transformed to ensure an overall sustainable value-based financing system. A structured model of finance transformation in healthcare is proposed in this article supported by evidential review, which discusses several fundamental and critical factors affecting finance transformation and explores some strategies that could help sustain the new financing models. Hopefully, this model can serve as a useful guide to healthcare systems embarking on finance transformation for long term cost sustainability.
\end{abstract}

Key Words: Healthcare, Cost, Finance, Transformation, Value, Model

\section{INTRODUCTION}

Healthcare cost is rising rapidly across the world, particularly among developed countries. In 2017, the U.S. health care spending rose 3.9 percent to reach $\$ 3.5$ trillion, or $\$ 10,739$ per person. ${ }^{[1]}$ This represented $17.9 \%$ of the gross domestic product (GDP), similar to that in 2016 and up from $17.7 \%$ in 2015. Public health expenditure and long-term care in OECD countries is set to increase from 6\% GDP in 2015 to $9 \%$ in 2030 and $14 \%$ by 2060 , unless governments can contain costs. ${ }^{[2]}$ Higher healthcare spending is attributed to the increasing needs of ageing populations including higher prevalence of chronic diseases ${ }^{[3]}$ and technological advances in medical care. ${ }^{[4,5]}$ Many countries remain heavily reliant on payroll taxes to fund healthcare. This however will decline as populations age. With concomitant declining fertility and population replacement rates especially among developed countries, ${ }^{[6]}$ governments need to find additional ways to finance healthcare.

Apart from using alternative sources such as "sin taxes", $[7,8]$ governments could ease budget pressures by changing the way healthcare is funded. Instead of funding healthcare based on volume or fee-for-service, governments can reward providers according to how well they optimize healthcare outcomes per unit of cost. In the context of this article, this is defined as "value-based" funding ("Value" in health care is classically defined as health outcomes per dollar spent). ${ }^{[9]}$ One could argue that the perspective of "value" differs across payers, providers and patients. To some providers, "value" could mean achieving good clinical quality, having confidence in treatment protocols and understanding the patient. On the other hand, "value" to patients may mean affordable out-of-pocket (OOP) cost, reasonable appointment times and confidence in a provider's expertise. ${ }^{[10]}$

${ }^{*}$ Correspondence: Harold Tan; Email: Harold_KB_TAN@nhg.com.sg; Address: National Healthcare Group, 3 Fusionopolis Link, \#03-08, (South Tower), Singapore. 
The transformation of a funding philosophy from volume- to value-based payments poses a greater challenge for providers than payers. This is because payers (traditionally governments) may merely re-design the budget, for example, as an amassed block of "bundles" stratified by diagnosis-related episodes based on historical utilization trends. The redesigned budget could even simply be a "capitated" block for funding all care. One key feature of such value-based funding is that the payer usually identifies and holds a prime provider accountable for the allocated budget, rather than deal with multiple providers. (For capitation, the payer usually holds an Accountable Care Organization [ACO] accountable while for bundled payments, the accountable body could be a regional hospital, managed care organization or consortium of primary or specialist care providers.) Besides financial accountability, the accountable provider is responsible for commissioning and working with other care providers while concurrently finding ways to innovate care, align incentives and satisfy patients. The accountable provider therefore becomes more directly responsible for the performance of the public healthcare system and may be held politically answerable for healthcare failures. (The introduction of value-based funding models seems in tandem with new public management i.e. increasing decentralization and devolution of government accountability in healthcare to public service and corporatized bodies, occasionally even contracted private providers. $)^{[11]}$

The concept of value-based healthcare financing gave birth to managed care entities and ACOs, mainly in USA. In countries where healthcare is traditionally centralized and publicly funded (e.g., UK, most European countries), value-based funding inspired shifts toward greater care commissioning and establishment of integrated care organizations which are similar to ACOs in the U.S. and are responsible for integrating and coordinating health and social care for the populations they serve. ${ }^{[12-14]}$

\section{THE NEED FOR A STRUCTURED MODEL}

Amid the challenges mentioned above, most healthcare systems tend to undergo value-based transformation in a more piecemeal rather than structured and systematic manner. This is primarily because transformation requires participation of many different players who are responsible for different parts of the health and social care system. Furthermore, there is yet any single governance or expert body that could converge multitudinous opinions on transformation and marshal a concerted transformation effort. There is also lack of incentives for any entity to lead change systematically. All these factors probably contribute to the dearth of published concepts and structured frameworks on this subject other than case studies of value-based transformation in different jurisdictions.

Published by Sciedu Press
For healthcare systems that are preparing to transform, they may need more comprehensive guidance and information from literature regarding the process of finance transformation, which is pivotal in changing behaviours and transforming care. There would be many factors to consider when designing new funding and patient payment models. McClellan et al. ${ }^{[15]}$ described a framework to guide accountable care reforms but did not focus on how the financing system should be transformed to effect care transformation. Burton ${ }^{[16]}$ described six competencies that sponsors of an Accountable Care solution need in order to succeed in the new value-based payment environment. However, the framework focused on the relationship between accountable care and population health management in the narrower context of data management solutions rather than broader fundamental requisites and factors influencing financial transformation.

\section{REVIEW, RELATE, REFINE: MODEL CON- CEPTUALIZATION AND METHODOLOGY}

In articulating the "how" of transformation, this article hopes to identify and deepen the understanding of the relationship between various factors that influence finance transformation and behavioural change that will bring about downstream care transformation, innovation and ultimately, cost sustainability. The article draws on the experience of different local stakeholders who are involved in the finance transformation journey of a local public healthcare group, including clinicians, care operations executives, financial officers and public health specialists. From the knowledge and perspectives shared through several discussions and deliberations, a preliminary model of finance transformation is first developed to articulate the financing models that need to be transformed and document a range of possible factors that are either fundamental to the design of the models or critical to the sustainability of the models. A review of literature available on various Internet sources is conducted, including broad search engines and more specific public health resources such as PubMed database, websites of health and social organizations and governments, online news on health finance and transformation, etc. From the literature review, one could have a better understanding of how each factor influences efforts to achieve value-based and sustainable healthcare and how such effects may promote or impede the success of the desired models. Some of the literature offered recommendations and potential strategies to overcome foreseeable barriers in transformation. This process helps to review the factors, strategies and potential derailers of significance and contributes to further refinement of the model. Figure 1 summarizes the methodology for developing the model including literature review. 


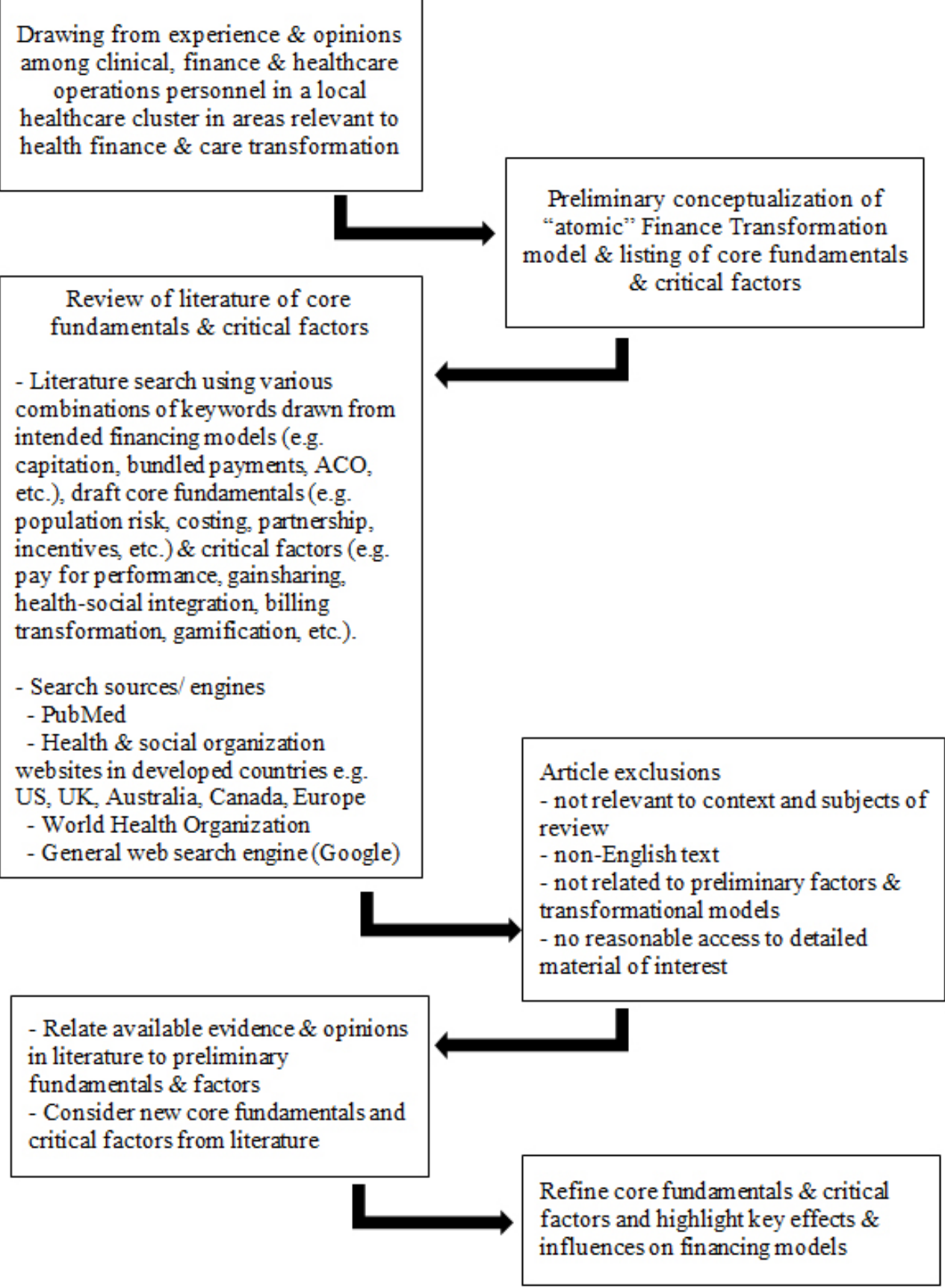

Figure 1. Flowchart on the "review-relate-refine" methodology in developing the finance transformation model

\section{4. "ATOMIC" MODEL OF FINANCE TRANS- FORMATION}

In this article, healthcare finance transformation is defined as a significant and systematic change in the way payers or consumers pay to provide or consume healthcare respectively in order to achieve overall cost sustainability for the healthcare system. It involves the transformation of three basic tenets of healthcare finance: payer funding, fund disbursement to providers and payment by patients. Invariably, finance transformation involves the adoption of financing innovation to drive behavioural changes among healthcare providers and patients such that incentives of different parties are aligned to achieve the transformation goals. Figure 2 shows a schematic of the proposed finance transformation model. This depicts the importance of "core fundamentals" that provide the basis for designing new models of funding, disbursement and patient payment, and a set of critical factors that could influence the effectiveness and sustainability of the new financing models. The overall transformation 
model is described as "atomic" in the broad sense that it figuratively and conceptually resembles the structural integrity of an atom with its core nucleic protons and orbiting electrons. Likewise, the long-term success of finance transformation de- pends on the strength of its core fundamentals and favourable critical elements for its stability and sustainability.

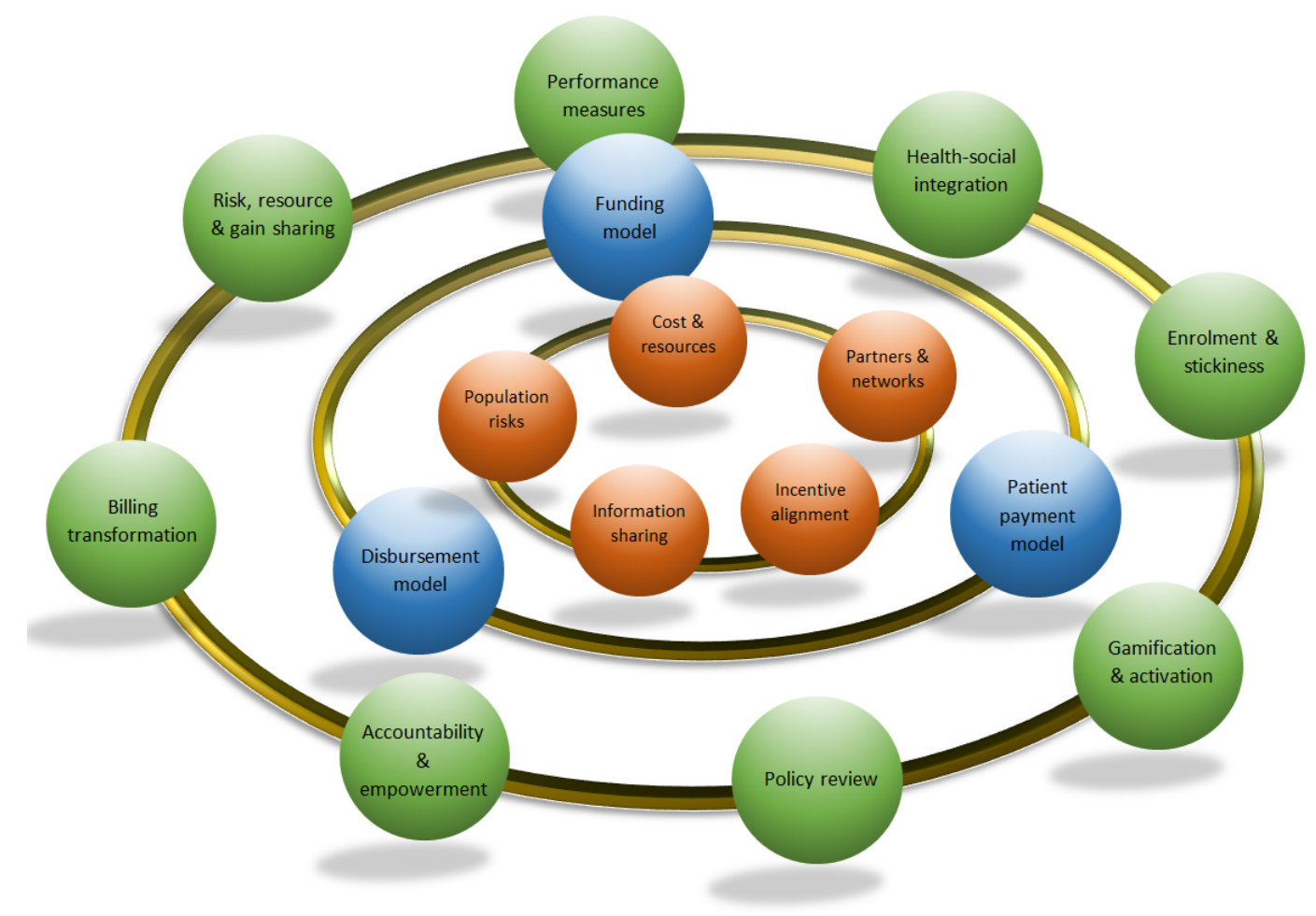

Figure 2. An "atomic" model of finance transformation in healthcare

5. TRANSFORMATIONAL FINANCING MODELS

These are the models that dictate the fundamental healthcare financing activities of funding, disbursement and patient payment. They are depicted in the middle ring of the atomic transformation model.

\subsection{Payer funding}

In many developed countries, payers traditionally fund providers based on the volume of services delivered. ${ }^{[17]}$ Increasingly, this has become the focus of transformation and more payers are experimenting with value-based funding models. Currently, the two most common value-based funding models are capitation and bundled payments. ${ }^{[18]}$ The aim of these models is to motivate or pressure the provider to provide care within the limits of a budget, which is computed based on how much care a person needs on the average within a time period defined by specific care episodes (bundles) or for all aspects of care (capitation). Providers will try to optimize care at the lowest cost possible in order to achieve greater budget savings (also known as "gains"). These models are usually accompanied by measurement of patient outPublished by Sciedu Press come indicators to ensure that care is not compromised. Such mechanics of funding potentially drive greater value in care, as providers become more cost-conscious when delivering care while maintaining reasonable clinical outcomes. The potential pitfalls of such funding models include denial of care, adverse selection, restricted choice of provider or poorer patient outcomes, ${ }^{[19]}$ but these may be overcome by a variety of regulatory, incentive and risk management measures to protect patients' interests. ${ }^{[20]}$ As discussed later, the success of these new funding models will depend on the accuracy of risk and cost projections and the validity of assumptions about how providers and patients respond to incentives and pressures.

\subsection{Fund disbursement}

Under a value-based funding framework, the way funds flow from payers to providers will also be transformed. Payers no longer pay providers individually but would commission a prime provider to be accountable for budget disbursement to secondary providers. This would be similar to contractual models used by clinical commissioning groups in the U.K. ${ }^{[21]}$ or ACOs in the U.S. ${ }^{[22]}$ Under such new disburse- 
ment models, prime providers must be competent in contracting and paying secondary providers. They must learn to foster trust and incentivize greater cooperation, integration and efficiency among its network of providers. There may be a need for the prime provider to ringfence a portion of the funds for secondary providers as rewards for meeting specific value-based performance and productivity targets. Planning on fund disbursement may inevitably converge on the issue of paying individual care providers, including designing a pay-for-performance $(\mathrm{P} 4 \mathrm{P})$ framework.

\subsection{Patient payment}

The third model for transformation relates to how patients pay for healthcare. Many developed western countries use taxation and social insurance as means to recover patients' share of healthcare costs. ${ }^{[23]}$ This could spare patients the need for OOP payment at the point of care. However, most developed countries including those with universal healthcare coverage require cost sharing for healthcare services primarily as a way to prevent moral hazard among patients. ${ }^{[24]}$ Such cost-sharing usually manifests as deductibles, co-insurance and/or co-payments at the point of care. Co-payments may be in the form of cash (or mobile pay transactions) or deductions from a mandatory health savings account, for example, in the Singapore Medisave model. ${ }^{[25]}$

Transformation of the patient payment model would depend on the society's healthcare philosophy and what patients value most when navigating the healthcare system. A philosophy of prudent healthcare consumption with avoidance of unnecessary spending would underpin a cost sharing model. Co-payment at the point of care also makes patients more price-sensitive and prevent the typical moral hazards associated with insurance. On the other hand, jurisdictions that eschew the use of cost sharing (e.g., Canada) believe that it would potentially increase overall cost of healthcare as patients would cut back on essential health services to the point that it would cost more to manage their deteriorated conditions when they re-enter the system. Although the reduction in service utilization due to cost-sharing was demonstrated in the RAND Health Insurance Experiment and other more recent studies, the evidence suggested that the impact of cost-sharing on utilization and health outcomes was more evident among older, poorer and sicker people. These groups were more likely to suffer health complications from reduced care utilization due to cost-sharing. ${ }^{[26,27]}$ This could explain why countries that introduced cost-sharing generally exempt these subpopulation groups.

Another important consideration is about how patients costshare for the healthcare services. Package pricing of chronic disease management services may be more effective than pay- per-visit in ensuring patients' stickiness with their providers, especially in a porous healthcare system where gatekeeping and empanelment is not mandated and patients are free to visit any care provider for subsidized care. Such stickiness is important for continuity of care and adherence to longterm treatment and follow-up. This pricing tactic and its effect on consumer stickiness is not new, as evident in other commercial service sectors involving computers and telecommunications. ${ }^{[28]}$ It could leverage on upfront OOP payment for the bundled services by the patient, who is then more likely to fully utilize the services for maximum value. When marketed together with higher ala carte prices of individual services, patients may be more likely to appreciate the bundled value. Furthermore, convenience can be an additional selling point for patients who want access to a complete suite of essential services at one location or procured by a single provider. This is particularly crucial when different healthcare services are provided by different providers, for example, hospital-based specialist services vis-à-vis home therapy services run by third sector providers. Patients with chronic diseases are often confused over the multiple types of care that they need, so packaging solves their problem with order and simplicity. Further to that, patients may also appreciate convenience in the form of single billing and a single point-of-contact for any financial counselling, service enquiries and assistance.

Specifically, package pricing is advantageous for promoting uptake of preventive healthcare. The lower income population groups may be parsimonious about spending on preventive care services such as health screening, immunization and smoking cessation. These services can prevent the development of serious conditions such as cardiovascular diseases and cancers, which are costly to treat. ${ }^{[29]}$ The lower income groups are more likely to suffer from such serious conditions, ${ }^{[30]}$ yet ironically, they have less access to preventive healthcare due to affordability issues. ${ }^{[31]}$ Preventive healthcare should therefore be packaged with primary care services to make it more affordable for lower-income patients.

\section{Core Fundamentals of Financing MODELS}

Core fundamentals are the foundation and recipe for transforming financing models. They embody the basic building blocks of new financing models, for example, determining population health risks, aligning incentives and working with care partners. These building blocks must be laid correctly and firmly to ensure that both financial and patient risks are managed optimally when operationalizing the financing models. 


\subsection{Population risks}

It is vital for a healthcare provider to determine the current and future health risks of its target population and take these into account when designing new financing models. Population health risks are often dynamic, changing with time in tandem with demographic, epidemiological, lifestyle and technological trends. Health risks may also vary among different population cohorts, ${ }^{[32,33]}$ since each cohort faces a unique time period of environmental changes and events that may impact on health, such as epidemics, disasters and global lifestyle transitions.

Upon knowing the range of population health risks, there is a need to prioritize these risks for resource planning and action. This forms the basis for stratifying the population into subgroups based on the calculated risks. It should be recognised that value-based funding may not be feasible for every type of health risk or healthcare service. For example, medical conditions that are sporadic, less predictable (e.g., trauma, disease outbreaks) or involve a high degree of treatment variation and uncertainty in patient response (e.g., rare cancers) may need to be excluded from global capitation. On the other hand, bundled payments are more ideal for conditions that can be clearly diagnosed and entail well-defined, protocolized care with measurable treatment outcomes (e.g., knee joint replacement). Likewise, it is challenging to bundle or capitate end-of-life (EOL) care funding due to prognostication issues and difficulties in defining the scope and magnitude of EOL care needed. Besides, it may be deemed morally and politically unsound to bundle or capitate funding for EOL care.

One challenge is the translation of risks into potential care needs and costs, particularly when considering needs for preventive care as well as interventions to slow frailty progression and functional decline. There is uncertainty over whether these care elements actually help to reduce longer term costs by indirectly reducing the burden of tertiary care, or would increase costs by adding more life years of care utilization. A simpler approach may be to assume that all risks are not preventable and will result in conditions that need tertiary care. However, such an assumption will only lead to sky-rocketing budgets, antithetical to the spirit of value-based care transformation. Evidential reviews of preventive $^{[29,34]}$ and frailty care ${ }^{[35,36]}$ are useful in guiding the choice of cost-saving or cost-effective interventions, but one should always bear in mind the strength and context of the evidence before adoption.

Population health risks may vary geographically due to differential population distribution by age and socio-economic status. In such instances, any new financing model that is ap- plied across all regions should be risk-adjusted accordingly. For example, bundles for diabetes management in a region with older or poorer patients may be priced higher to account for potentially higher treatment and rehabilitation costs.

\subsection{Costs and resources}

Apart from estimating costs related to health risks and care needs of the population, other ancillary costs should be considered when new integrated, value-driven care models are introduced. For example, if new care models promote greater right-siting and integration between health and social care, greater workload in case management and coordination of services between different care settings (including health vis-à-vis social care) would be expected. This could require additional funding and manpower resources at least during the incipient stage until the new care model reaps sufficient savings. Case management costs may vary depending on the model of case management adopted, scale of operations, availability of coordinating services, patient case-mix, and the need for preventive services. ${ }^{[37]}$

With right siting of care to the community, patients' informal caregivers may inevitably shoulder greater care burden and costs which are not apparent to the healthcare providers or payer (e.g., leave from work, loss of productivity, hired domestic care, etc.). Such costs can be significant especially for patients with debilitating conditions like neurological diseases (e.g., multiple sclerosis, Parkinson disease ${ }^{[38]}$ and dementia. $)^{[39,40]}$ In planning the financing model, one should understand the implications on budget sustainability and take into account additional funding needed for patients who lack informal caregiver support.

A major challenge lies in the accuracy of costing care services and activities. There is also great variation in costing among different healthcare systems due to the lack of a universally accepted costing methodology. The main causes of such variation and suboptimal costing accuracy include the irregularity of apportioning overhead costs, valuing fixed assets and determining depreciation costs. ${ }^{[41]}$ Although ideally there should be micro-costing ${ }^{[42]}$ for every service to ensure accuracy, this would be labour-intensive and expensive. (Micro-costing is a cost estimation method that involves the "direct enumeration and costing out of every input consumed in the treatment of a particular patient". This definition is drawn from Gold et al. 1996. A common example of microcosting is Activity-based costing [ABC].) Furthermore, there may not be adequate detailed data captured to cost every input used in the treatment of every patient. Nonetheless, it has been shown in some studies that micro-costing is useful for costing new interventions as well as services with highly variable practices. ${ }^{[43]} \mathrm{A}$ framework to standardize the 
micro-costing approach across different services within the same system would be useful as it allows cost-effectiveness comparisons of different care initiatives in transformation pilots and helps to demonstrate the impact of new financing models on care costs and value.

\subsection{Partners and networks}

The success of a value-based funding model will depend on the cooperation of different care providers to deliver integrated care across different care settings. Some sacrifices and compromises among the providers may be necessary in order to produce better overall efficiency and net gains for the whole system. This has to be based on good relationship and trust among the various care partners. Partnerships are equally important when transformation of patient payment models is involved. For example, the prime care provider may need to work with non-health sector players to provide attractive benefits (e.g., lifestyle perks, retail discounts) to encourage subscription to chronic care packages.

It is therefore important that the quality of partnership and cooperation between care providers be evaluated regularly so as to ensure that the partnership network continues to function optimally. Some factors that may affect the quality and sustainability of healthcare partnerships include organizational settings, support structures, purpose and goals, communication, relationships and professional flexibility. ${ }^{[44]}$ These areas should be measured and monitored closely, so that any issues that threaten the partnership can be resolved promptly. A review of collaboration measurement tools revealed that the Ødegard's PINCOM-Q tool was the most appropriate. ${ }^{[45]}$ This tool assesses, inter alia, motivation, role expectations, communication and organizational culture that are related to interdisciplinary and interinstitutional partnerships. Collaboration measurement tools may also be used to monitor partnership changes over time including before and after organizational transformation which may occur as part of finance transformation.

\subsection{Incentive alignment}

Payers and providers may have different goals in mind when entering a health service contract. Likewise, patients' goals and values are different from those of their care providers. It is important that each party remains incentivized to maintain an effective tripartite relationship. Hence, the incentives that drive the financing model must be aligned. Payers often aim for cost efficiency, fiscal sustainability and even profitability (e.g., insurance companies) so that healthcare budgets do not escalate year-on-year. Other than employed providers, payers will need to incentivize contracted providers to improve on care efficiency and productivity as part of the commission- ing strategy. The reward structure could be in the form of gain sharing or extemporaneous funding and must be agreed upon between the payer and provider. It is more challenging to align incentives between providers and patients, as values among the patient population are more diverse. Some patients may be more price-sensitive and are not particular about service quality, while others may not mind paying more for convenience and shorter waiting times. A patient outreach programme on value-based healthcare is needed to set the right expectations for all patients and have them embrace a common value, e.g., to stay healthy and functional. Patients also need to have greater ownership for their own health, and be empowered for better health literacy and self-care. This is critical for achieving a sustainable, patient-centred and cost-effective healthcare system. ${ }^{[46]}$

\subsection{Information sharing}

Within a care ecosystem, patients often flow from primary to tertiary care and back to the community, and will transit through different care providers. Good continuity of care throughout the patient's journey is contingent on proper care handovers and coordination. In addition to effective communication, good therapeutic provider-patient relationship and care flexibility, proper care handovers will require excellent information transfers. ${ }^{[4]}$ This is only possible if the different care providers share information about their patients' health and socioeconomic status and have access to up-todate patient data for making appropriate and timely clinical decisions.

Concerns over data privacy and cybersecurity are often heightened when there are intentions to share data more widely, but these should never become barriers to patient care which is paramount. Blanket internet surfing separation and other blunt cybersecurity measures should not be implemented at the expense of preventing sharing of health information among providers. Instead, targeted and sophisticated measures such as stronger patient data encryption with robust algorithms and personnel training to identify phishing attacks are more appropriate preventive mechanisms for data sharing systems. ${ }^{[48]}$ Likewise, the use of secure digital workspace $^{[49]}$ or intricate network segmentation ${ }^{[50]}$ are more refined and thoughtful cybersecurity solutions.

For effective patient empowerment and self-care, information about patients' own risks, conditions and biomarkers should be readily accessible. This should be coupled with sufficient medical information resources so that patients and caregivers can be more knowledgeable and better manage their conditions and risks. Information on self-help and patient assistance schemes should be automatically channelled to electronic health records for patients' reference, where 
warranted by patients' needs. This will improve efficiency in addressing health and social issues especially among indigent and less privileged patients.

\section{Critical factors for SUStaining Fi- NANCING MODELS}

With new financing models, both payers and providers face two main risks: the risk of financial failure where funds run out and care cannot be provided, and care failure where care is suboptimal, inadequate or withheld from patients resulting in poor patient outcomes. Such risks may materialize in the longer term if behavioural changes of providers or patients as intended by new financing models are either unsustainable or excessive. For example, providers may stop right-siting patients to the community or resume using costly medical technology. Likewise, patients may decline referrals to community-based care due to inconvenience or lack of social support. On the other hand, providers may become too averse to financial risks and cut back on essential care. Medicalization and overdiagnosis may also emerge in response to increased societal consciousness of conditions and predilection to seek medical solutions. ${ }^{[51]}$ This is likely to result from improved public health education and outreach efforts and could lead to unnecessary healthcare consumption.

It is therefore important to recognise certain factors that will influence the success of new financing models and develop strategies and measures that will sustain desired changes in behaviours and care approaches as a result of value-based financing approaches. Depending on the socio-political context of each region, some conceptual ideas discussed below may require support from the government and other thirdparties for implementation.

\subsection{Performance measures}

Generally, anything that is not measured will not be improved, notwithstanding that in certain areas of transformation, improvement may still happen based on qualitative observations, intuitive logic and culture ${ }^{[52]}$ Nonetheless, to achieve cost sustainability in healthcare using value-based financing models, performance measures that track quantitative cost-related outcomes must be monitored. The three key groups of outcome measures to track are cost, utilization and patient outcomes. Cost measures are the most direct in determining cost savings from transformation. Utilization measures when used in conjunction with a pre-defined arbitrary unit cost may also help track costs. In addition, certain utilization measures are proxy measures for patient outcomes. For example, rates of readmission or repeat visits to emergency departments may indicate the degree of suboptimal clinical outcomes from initial care.

Published by Sciedu Press
Actual patient outcome measures usually entail conditionspecific or functional assessments, occasionally with biomarker levels. On their own, patient outcome measures only measure quality of care. When combined with cost measures, one can derive an index of value, i.e., how much quality is achieved per unit cost. Baseline value indices should be used for pre- and post-transformation comparison. Where available, benchmark value indices from other health financing systems may be used for comparison. This is however not so crucial as the contexts of clinical practice in different healthcare systems are often different and therefore outcomes are not directly comparable. Moreover, every healthcare financing system will define its own threshold of success, regardless of how other systems perform.

Performance measures can be used as a mechanism to reward providers for achieving the desired value in care (i.e., pay for performance or $\mathrm{P} 4 \mathrm{P}$ ). This could incentivize providers to innovate care for better cost-effectiveness while maintaining optimal patient outcomes. P4P incentives may sustain behavioural change but they cannot exist without performance measures. The design of $\mathrm{P} 4 \mathrm{P}$ incentives will however require caution and much deliberation, as historical evidence including systematic reviews have not been conclusive on their effectiveness or whether their benefits outweigh potential pitfalls. ${ }^{[53]}$ Many studies have also not convincingly adjusted for confounding effects of other improvement initiatives. ${ }^{[54]}$ A more recent longitudinal study demonstrated the positive effects of $\mathrm{P} 4 \mathrm{P}$ on performance improvement, but suggested to focus on the design of the performance indicators and targets to be rewarded (i.e., what to reward). ${ }^{[55]}$

\subsection{Sharing resources, gains and risks}

The healthcare landscape will change with new financing models. Traditionally, care is mostly delivered in institutions, e.g., hospitals, clinics and nursing homes. Increasingly, value-based financing models are putting pressure on care providers to deliver care in the community or patients' homes so as to reduce the need to build more healthcare institutions to cope with rising demand. Hospitals therefore become accountable not only for inpatient care but also post-discharge care in the community.

Other than providing care directly, the hospital may contract or partner with other providers to deliver community-based care. Conceptually, the funding for each patient will cater to the whole care value chain from hospital to community including any readmissions as well as follow-up outpatient visits within a reasonable time period. Such a funding model will motivate providers to optimize utilization for greater savings. The Centers for Medicare and Medicaid Services (CMS) uses this model in their Bundled Payments for Care 
Improvement (BPCI) initiative. ${ }^{[56]}$ With such funding transformation, it is imperative for providers to share and maximise the use of their collective resources. For example, hospital-based diagnostic and treatment capabilities may be tapped by community and primary care providers without duplicating capabilities in the community. This will help reduce overall operational costs, improve the margins of earnings and enable greater viability and sustainability of value-based funding.

The corollary of such arrangements is that besides resources, care partners will also need to share gains and risks. A formula for apportioning gains that is co-developed by all collaborating care providers should be established. At the macro level, this can be based on proportionate contribution to resources or initiatives that help reduce costs (e.g., reduce length of stay, reduce implant pricing). Gainsharing arrangements should also target sustained long-term improvement rather than short-term savings. ${ }^{[57]}$ For each provider, gains should be shared internally at the departmental level using P4P measures for a better effect on future performance improvement. ${ }^{[58]}$ Prior to implementation, some rules and safeguards should be established for gain sharing primarily to protect patients' interests, prevent case-mix manipulation and set gain limits. ${ }^{[59,60]}$

Risk sharing among providers typically refers to sharing of potential financial loss. Prior to a risk-sharing arrangement, payers (including prime providers who commission care partners) should adopt a risk management approach and watch out for factors that might put the value-based financing model at risk of failure. For example, payers need to be perceptive and practical in the choice of providers and their capabilities in terms of governance, leadership, infrastructure and technology especially analytics. ${ }^{[61]}$ Payers must also be prepared to support their providers by sharing pertinent information such as population risks and care costs data, and setting a stop-loss mechanism to prevent provider failure. Such a mechanism can be accompanied by a limit to gain-sharing to avoid sharing surplus that is generated by pure chance rather than attributed to providers' performance.

\subsection{Health-social integration}

Population groups with lower socio-economic status are associated with higher healthcare utilization and costs. ${ }^{[62]}$ Social determinants of health must therefore be addressed to ensure healthcare cost sustainability. In jurisdictions where population-based integrated health and social care approaches are used (e.g., U.S. Kaiser Permanante, Alaska's Nuka System of Care, Germany's Gesundes Kinzigtal, New Zealand's Counties Manukau, Sweden's Jönköping County Council), hospital utilization decreased or slowed down re- markably. ${ }^{[63]}$ Healthcare providers are well poised to concurrently tackle social issues, more so than for social care providers to tackle health issues. This is because people with social problems may not be identified for assistance until they present as patients with health problems. In this respect, it is important for the social care agenda and budget to be brought under the larger health mandate. This allows healthcare providers to manage patients' conditions in their social context such that any assistance rendered could be more holistic and cost-effective. For example, it could address the phenomenon of social stayers in hospitals and prevent unnecessary admissions. Healthcare providers should also have admitting rights to social care homes so that they can discharge suitable patients who do not need hospital care to such homes.

Historically, the sharp demarcation of health and social care systems is prevalent globally and has been described as a "Berlin Wall". ${ }^{[6]}$ A major barrier of health-social integration cited has been the lack of integration of budgets across these sectors. ${ }^{[65]}$ There are several purported benefits of health-social integrated funding, including improved access to a right mix of community-based services which could help reduce unplanned admissions and readmissions, reduce length of hospital stay through better community support, reduce total costs and improve patient experience of care. Although these benefits demonstrated by studies so far have not been highly impactful, this is likely due to challenging study methodologies and inability to isolate the effects of financial integration from confounders. ${ }^{[66]}$

Health-social financial integration can be achieved in several ways. The most direct yet challenging approach involves structural integration which combines health and social care responsibilities within a health body under a single management. This is often impeded by legacy structures and the conundrum of "your integration is my fragmentation"[67] which could take substantial change management effort and time to overcome. A less harrowing fix may be to set up a new combined health-social structure that pools some resources, staff and management. One party then acts as host to undertake the other's function in the new structure. An even simpler level of integration involves one party commissioning the other party to provide services based on a joint contractual agreement. Other arrangements such as transfer payments, cross-charging and aligned budgets between parties are strictly not integration but merely financial partnership in different forms. Without true health-social integration (at least structurally), there will always be differences in governance, management approach, culture and regulation across different organizations. Such differences will impact on inter alia staff teamworking ability, notions 
of trust and control, professional philosophies and values, and quality of relationships - these are critical factors that influence the effectiveness of health-social integration. ${ }^{[65]}$

\subsection{Billing transformation}

Administrative costs account for a significant proportion of total healthcare expenditure. A study comparison of hospital administrative costs in eight nations showed that the administrative costs in U.S. healthcare was proportionately the highest. ${ }^{[68]}$ Studies also showed that most of the administrative costs in the U.S. healthcare system were attributed to billing and insurance-related activities, which had significantly increased due to a multi-payer system as compared to simplified financing. ${ }^{[69]}$ Billing costs could make up 3\% to $25 \%$ of physician professional revenue per patient encounter. ${ }^{[70]}$

The data suggests that there is still much room for improving billing processes. The healthcare system appears to lag behind other industries in areas of billing transparency, customer self-service, and electronic and mobile billing. ${ }^{[71]}$ With the advent of value-based care, ACO models and population health, there is greater need for enhanced billing algorithms, workflows and analytics. With more dynamic patient movement across different care settings, billing algorithms need to change from individual provider billing to more streamlined and consolidated billing by the prime provider, while maintaining transparent bill itemization for patients to compare and monitor individual service and product charges. More intelligent workflows are needed to optimize resources for billing work (e.g., centralization of billing approvals and patient communication). Most importantly, billing data analytics technology needs to be enhanced to deliver appropriate lessons back to the billing practices. ${ }^{[72]}$ Billing data can be a rich source of data to better understand the healthcare operations, efficiency gaps, care utilization patterns and trends, and even population risks.

As patients' expectations rise, the perceived values of convenience, speed and flexibility in billing will also increase. This is where technology will play a critical role in enhancing patient satisfaction. Providers should fully exploit digital and mobile billing platforms to align with patients' desired values. This will indirectly increase patients' acceptance of care plans that entail more right-siting with multiple providers and community care settings, thus indirectly supporting valuebased financing models. Mobile billing and payments are taking off steadily in the healthcare sector, including in developing countries. ${ }^{[73]}$ Mobile billing could potentially reduce billing transaction costs, particularly in collecting payments from hard-to-reach locations. ${ }^{[74]}$ It also provides the opportunity to extend quick financial aid to indigent populations and could potentially reduce the burden of late or defaulted payments due to its inherent convenience. With the digitization of health services, mobile billing could ride on existing or emerging health phone apps to provide a more seamless experience that encompasses inter alia medical appointment management, health information, health monitoring and medication compliance. Inevitably, cybersecurity concerns will grow pari passu with the increasing adoption of electronic and mobile payments. ${ }^{[75]}$ However, it is unlikely that these will dampen the technology adoption rate. Rather, such trends will provide strong impetus for further advancements in cybersecurity.

\subsection{Accountability \& empowerment}

A framework of accountability should be developed and implemented for providers in charge of the population's healthcare needs. A prime provider, which could be a single health care organization or an alliance of providers, should possess certain key capabilities and competencies before it can assume the role of an ACO. These include a formal legal structure and governance, stewardship in linking providers along the care continuum, health information technology, and structures to negotiate and manage funding contracts. ${ }^{[76]}$

Payers, particularly governments, should empower the ACO with the authority for commissioning, quality assurance and relevant regulatory functions. Such administrative delegation, which is an extension of decentralization in healthcare systems as described by the World Health Organization ${ }^{\text {[77] }}$ and the European Observatory on Health Systems and Policies, ${ }^{[78]}$ is necessary to hold the ACO effectively accountable in three principal areas: financial, performance and political, with the latter being a consequence of the former two. ${ }^{[7]}$ More specifically for finance transformation, administrative delegation empowers the ACO to align the behaviours of care partners and patients to achieve value-driven outcomes for the system. Apart from being accountable for fiscal prudence, care access and quality of care, the ACO should also be authorised to impose sanctions on partner providers (both organisations and individuals) for unethical behaviours and dereliction of duties. It should also have powers to dictate the manner for resolving provider-patient disputes within its system to minimize litigation. Strong governance by the ACO over its commissioned service providers will help to engender public trust and confidence. This is especially important in larger jurisdictions where it is more challenging for central or municipal authorities to regulate individual service providers.

ACOs should also be empowered with the ability to initiate and operate relevant health care (insurance) plans for their enrolled populations, particularly in larger jurisdictions where 
there is sufficient critical mass for effective risk pooling. A clear advantage of this is that the ACO is close to the ground and thus familiar with the risks and utilization patterns of its population and the capabilities of its care partners. The care plans can be customized to address both the population's needs and the ACO's financial risks more adequately, especially if the payer only subsidizes a portion of healthcare (i.e., a selected range of medical conditions and treatments) or certain needy population groups (e.g., elderly, poor).

\subsection{Enrolment \& stickiness}

Population-based capitation requires the captive population to be enrolled and empanelled to a network of providers. Enrolment may be renewable on a yearly basis or at longer intervals. Since capitation is computed based on projected costs of all care that each person needs within a defined time period, it is necessary to lock in each population member to a specific care plan. Although politically, payers often provide patients with a choice of healthcare plans, providers and services, allowing patients the freedom to enter or exit capitated care plans at their own will could result in a complicated gamut of backend transfer payment processes and coordination work that would incur higher administrative burden and resources. In jurisdictions where patients need to co-pay for healthcare services (e.g., OOP user fees), a more restrictive enrolment has the added opportunity to commit patients to their care plans, especially if co-payment is collected in advance for a defined period and range of services. It is also easier to incentivize enrolled population members to take up preventive care such as adopting healthy lifestyles and undergoing regular health screening, which is known to reduce downstream tertiary care utilization. With the savings from reduced utilization, the providers can offer members rebates for subsequent care plan renewals or better rewards.

\subsection{Gamification \& activation}

Not all enrolled population members are motivated to keep themselves healthy. Younger, less educated and lower income groups appear less likely to adopt overall healthy lifestyles. ${ }^{[80]}$ Such members, particularly those at risk, may cost the system dearly at a later stage when they wind up in hospitals with complicated chronic diseases and multiple co-morbidities. This is where the role of gamification comes in, which helps to motivate people via a range of different psychological core drives ${ }^{[81]}$ by using an architecture of several persuasive strategies combined. ${ }^{[82]}$ As long as it is well-sustained, gamification will keep people activated to continue performing activities beneficial to their health, even though it may not be their intention to do so.

Gamification has been proven in a few studies to be effective in influencing behaviours for better health and well-being in the short term, particularly physical health. ${ }^{[83]}$ Certain game elements are also demonstrated to be more effective than others in addressing specific psychological needs. ${ }^{[84]}$ Nonetheless, there is still lack of evidence to demonstrate the long-term effectiveness or cost-benefit of gamification in sustaining behavioural change. Ideally, the benefits in terms of overall reduction in utilization and costs should outweigh the investment in a gamification system. To sustain behavioural change, a combination of multi-pronged gamification tactics and game design elements may be necessary to cater to the diversity of psychological needs across the population. Gamification tactics and game design elements should also be dynamic as people's core motivational drives may change over time as they pass through various life events and experiences.

\subsection{Policy review}

It is possible for value-based funding models such as care bundles to fail due to legacy policies that impede care transformation initiatives such as right-siting and self-directed patient care. Such policy barriers may be financial in nature, for example, discrepant subsidies or reduced access to financial aid. Others may concern the lack of capacityor capability-building of community-based long-term care resources due to over-dependency on third sector service providers and possibly over-optimism about their operational capabilities. ${ }^{[85]}$ (Locally known as the "many helping hands" approach. The memorandum from Amicus precisely and succinctly summarizes the role of the third sector as a valuable partner to public services, not a replacement. The third sector only adds value to public services, and should not be expected to take over these services [Public Administration Select Committee, UK, 2008].) This is compounded by poor coordination of services, piecemeal intervention and resource constraints, causing overall poor service user experience. ${ }^{[86]}$ (These short-comings were prevalent in the local social care sector and are still being addressed [Mathi \& Mohamed 2011].)

Other policy barriers may entail care boundaries that limit certain care activities to specific settings. For example, smaller community hospitals may be prohibited from providing advanced diagnostic services (e.g., computed tomography) that are allowed only in bigger general or teaching hospitals. These rules may have been introduced to limit the use of medical technology in order to control rising healthcare costs. Such care boundary policies would however be irrelevant in a value-based funding model which transfers financial risks to providers by setting bundle limits. With a fixed budget, all providers sharing the bundle would have to collaboratively 
deliver each care episode in the most cost-efficient manner in order to yield savings. Besides sharing resources and functioning like an integrated care ecosystem, the providers are likely to exercise prudence in using technology to keep their costs low and maximise potential gains. Furthermore, it would be illogical to require patients to be managed in high cost settings such as an acute hospital if the same clinical needs can be met in lower cost settings (e.g., smaller hospitals, ambulatory centres, nursing homes, etc.), provided there are no encumbering issues such as inconvenience to patients or inadequate capacity.

Providers should therefore constantly negotiate with payers and policymakers to review and possibly rescind or change irrelevant policies that impede finance transformation so as to enable more funding for community-based healthcare services. This will make such services more affordable and accessible to patients, who are then more likely to accept care and finance transformation initiatives.

\section{USE OF MODEL FOR TRANSFORMATION PLANNING}

Table 1 summarizes the importance of the core fundamentals to the development of the desired funding, disbursement and/or patient payment models. Table 2 summarizes the pos- sible mechanisms of influence exerted by critical factors that may affect the success and sustainability of value-based financing models. These are supported in part by the literature review and moderated by further logical inference and expert opinion. Conceptually, healthcare systems which are establishing value-based financing models should ensure that they have the necessary elements to make them work, but even before that, they need to uncover potential blind spots. For example, the lack of awareness and failure to project certain population risk trends could lead to severe underestimation of true care needs and costs for the population. Similarly, without alignment of incentives among payers, providers and patients, there may be no consensus for any financing model. Planners could use this model to take stock of the fundamentals and factors and ensure that these are thoroughly considered and accounted for when developing new financing models. It is also important to recognise that a balance of all factors must exist to maintain stability of the desired financing models. Overemphasis and excessive investment of efforts and resources in any factor at the expense of others could risk compromising the needed equilibrium for success. This structured model could enable planners to appreciate the scope of issues and carefully plan their resources for implementation.

Table 1. Importance of core fundamentals to developing desired funding, disbursement and patient payment models

\begin{tabular}{|c|c|c|c|c|}
\hline $\begin{array}{l}\text { Core } \\
\text { Fundamentals }\end{array}$ & Key Considerations & Funding Model & $\begin{array}{l}\text { Disbursement } \\
\text { Model }\end{array}$ & Patient Payment Model \\
\hline \multirow[t]{2}{*}{ Population risk } & $\begin{array}{l}\text { Historical \& current data on } \\
\text { population risks pertaining to } \\
\text { chronic disease \& frailty } \\
\text { Predictive model to project } \\
\text { population risks }\end{array}$ & $\begin{array}{l}\text { Basis for determining scope of } \\
\text { care \& costs needed to compute } \\
\text { funding }\end{array}$ & & $\begin{array}{l}\text { Basis for determining } \\
\text { scope of care \& costs } \\
\text { needed to compute } \\
\text { funding \& patients' share } \\
\text { of costs }\end{array}$ \\
\hline & $\begin{array}{l}\text { Geographical-based } \\
\text { adjustment of risks }\end{array}$ & $\begin{array}{l}\text { Basis for risk and funding } \\
\text { differentiation to ensure } \\
\text { equitable care access }\end{array}$ & & $\begin{array}{l}\text { Ensure patients' share of } \\
\text { costs corresponds with } \\
\text { their risks \& care needs }\end{array}$ \\
\hline $\begin{array}{l}\text { Costs \& } \\
\text { resources }\end{array}$ & $\begin{array}{l}\text { Precision \& reliability in } \\
\text { costing direct and indirect care } \\
\text { activities \& services } \\
\text { Fund \& resource injection for } \\
\text { new support capabilities for } \\
\text { care transformation }\end{array}$ & $\begin{array}{l}\text { Basis for accurate computation } \\
\text { of funding } \\
\text { Ensure new funding \& care } \\
\text { models are sufficiently } \\
\text { resourced for implementation }\end{array}$ & $\begin{array}{l}\text { Basis for proper } \\
\text { calibration of funding } \\
\text { disbursement \& } \\
\text { resource allocation to } \\
\text { providers }\end{array}$ & $\begin{array}{l}\text { Basis for accurate } \\
\text { computation of patients' } \\
\text { share of costs }\end{array}$ \\
\hline $\begin{array}{l}\text { Partners \& } \\
\text { networks }\end{array}$ & $\begin{array}{l}\text { Competent partners \& stable } \\
\text { care networks }\end{array}$ & $\begin{array}{l}\text { Basis for initiating } \\
\text { cross-setting value-based } \\
\text { funding }\end{array}$ & & \\
\hline $\begin{array}{l}\text { Information } \\
\text { sharing }\end{array}$ & $\begin{array}{l}\text { Reliable data sharing platform } \\
\text { accessible to all care partners }\end{array}$ & $\begin{array}{l}\text { Cornerstone of cross-setting, } \\
\text { shared care which is basis for } \\
\text { value-based funding models }\end{array}$ & & \\
\hline $\begin{array}{l}\text { Incentive } \\
\text { alignment }\end{array}$ & $\begin{array}{l}\text { Aligned incentives between } \\
\text { payers, providers \& patients } \\
\text { with common goals }\end{array}$ & $\begin{array}{l}\text { Basis for transforming to a } \\
\text { value-based funding model }\end{array}$ & $\begin{array}{l}\text { Basis for providers } \\
\text { agreeing to } \\
\text { commissioning terms } \\
\text { in disbursement } \\
\text { model }\end{array}$ & $\begin{array}{l}\text { Basis for patients agreeing } \\
\text { to subscribe to payment } \\
\text { model }\end{array}$ \\
\hline
\end{tabular}


Using this model, one may also better appreciate the areas where certain stakeholders could potentially influence the impact of some fundamentals and factors on the financing models. For example, if policymakers are not prepared to integrate health and social sectors, it could affect the operationalization of cross-setting care bundles and make it more challenging to design a holistic patient cost-sharing package that covers both health and social services. In jurisdictions where care partners have significant alternative revenue sources such as charitable donations or private patients, interests in value-based commissioning and collaboration in accountable care may be lukewarm, thus threatening the viability of financing and care models that depend on partner support.

Table 2. Possible mechanisms of influence of critical factors on the performance of value-based financing models

\begin{tabular}{|c|c|c|c|c|}
\hline \multirow[b]{2}{*}{ Critical factors } & \multirow[b]{2}{*}{ Key considerations } & \multicolumn{3}{|c|}{ Possible mechanisms of influence on financing models } \\
\hline & & $\begin{array}{l}\text { Cost } \\
\text { sustainability }\end{array}$ & $\begin{array}{l}\text { Performance } \\
\text { accountability }\end{array}$ & $\begin{array}{l}\text { Patient } \\
\text { experience }\end{array}$ \\
\hline $\begin{array}{l}\text { Performance } \\
\text { measures }\end{array}$ & $\begin{array}{l}\text { Use of value-based performance measures to guide } \\
\text { pay-for-performance }\end{array}$ & $\checkmark$ & $\checkmark$ & \\
\hline \multirow{2}{*}{$\begin{array}{l}\text { Sharing } \\
\text { resources, gains } \\
\text { \& risks }\end{array}$} & Risk management framework & $\checkmark$ & $\checkmark$ & \\
\hline & Provider support, stop-loss mechanism, gain limits & $\checkmark$ & $\checkmark$ & \\
\hline $\begin{array}{l}\text { Health social } \\
\text { integration }\end{array}$ & Health-social structural \& funding integration & $\checkmark$ & $\checkmark$ & $\checkmark$ \\
\hline $\begin{array}{l}\text { Accountability } \\
\text { \& empowerment }\end{array}$ & Delegated legal \& regulatory powers to ACOs & $\checkmark$ & $\checkmark$ & $\checkmark$ \\
\hline $\begin{array}{l}\text { Enrolment \& } \\
\text { stickiness }\end{array}$ & Enrolment \& empanelment to provider network & $\checkmark$ & $\checkmark$ & $\checkmark$ \\
\hline $\begin{array}{l}\text { Gamification \& } \\
\text { activation }\end{array}$ & Multi-pronged gamification \& incentive initiatives & $\checkmark$ & & $\checkmark$ \\
\hline \multirow{2}{*}{$\begin{array}{l}\text { Billing } \\
\text { transformation }\end{array}$} & $\begin{array}{l}\text { Enhanced billing algorithms, workflows \& } \\
\text { analytics }\end{array}$ & $\checkmark$ & & $\checkmark$ \\
\hline & Billing digitization & $\checkmark$ & & \\
\hline Policy review & $\begin{array}{l}\text { Regular engagement with policymakers to remove } \\
\text { policy barriers }\end{array}$ & $\checkmark$ & & $\checkmark$ \\
\hline
\end{tabular}

\section{Limitations AND POTENTIAL PITFAlls}

The proposed model for finance transformation takes into account a comprehensive range of considerations that may affect the success of transformation efforts. Even so, one will never have complete knowledge and appreciation of the different interactions between various factors and attributes of any healthcare system, not to say predict the outcomes of all conceivable interactions. While there is definitely ample room for further deeper literature reviews, a potential derailer in implementation may be the failure to accurately predict the patient's response to new care models and augmentative strategies, which may not be as similar to what is generally documented in literature or as rational as we expect. Cultures, values, beliefs and mental models vary widely among different ethnic populations and across different socio-political contexts, and these normally determine what patients truly value and guide them in their care choices. Yet, no one ever fully understands how these translate to actual patients' decisions and actions in different environments.
Furthermore, the fundamentals and critical factors discussed under the conceptual model are not exhaustive, as they are contextualized to a limited range of published or reported literature and local experience which may differ vastly from unreported experiences in many other jurisdictions.

The conundrum therefore compels the need to prospectively study service utilisation and cost patterns in a form of pilots to test the validity of assumptions made as part of transformation planning. Provided that care decisions and choices at the population level do not fluctuate extensively within short periods of time (e.g., within 5 years), the outcomes of a prospective pilot may reasonably contribute to further learning and justifications for full implementation and mainstreaming of the transformational models. Historical data may serve as a baseline from which pilots are launched. Some predictive models based on others' experiences and/or relevant trends of associated attributes could help test the accuracy of initial estimations and be further refined for actual implementation. Alternatively, predictive models can be 
validated by applying retrospective data and comparing the predicted results with actual data.

To get buy-in from care partners and clinicians, one needs to establish trust and provide a guaranteed "no worse off" provision to smoothen the transformation journey, at least for a start. This may entail additional seed funding to stand by for compensating potential losses, or to kickstart experimental work processes that will catalyse care and funding changes in the new direction. Concerns and lamentation about infrastructural and manpower support for transformation are common, and should be concurrently addressed with the pilots.

A potential bias when piloting a new care and funding model is that care might become more optimal than if it were business-as-usual. Unless clinicians and other healthcare professionals are blinded to the pilot, they may be pressured to practise more diligently and be more alert to potential care blind spots. Although this is beneficial for patients, it could increase care costs which may attenuate or even cancel out the cost savings that could otherwise be demonstrated by the pilot. Where preventive care is tested in a pilot, overzealous efforts may be made to deliver the services which could lead to increased case detection and patient load and consequently higher utilization and costs rather than net cost savings. Likewise, some of the factors depicted in the model such as patient stickiness and gamification may improve patient care but at higher administrative costs, may well render transformation less viable.

In healthcare systems where patient co-payment at the point of care constitutes a significant proportion of a provider's operating revenue (e.g., for commissioned private or semiprivate providers), implementing value-based funding which logically leads to fewer visits, admissions and/or length of admissions, will reduce overall volume and revenue for the provider. If this reduction in revenue is not outweighed by savings from value-based transformation or at least reasonably compensated by extemporaneous funding by the payer, the provider will be disadvantaged and will not be motivated further to transform care, even if transformation helps save costs for the whole system.

Efforts by service providers to improve efficiency and care value are usually ongoing, irrespective of any national transformation agenda. These efforts are motivated by the prospect of significant productivity gains for re-investment in further innovation and greater care value. Amidst their eagerness to champion the national agenda and publish declining or stabilizing healthcare cost figures to demonstrate better care value within a given timeframe, payers and policymakers need to be cognizant of the law of diminishing returns and consider how to manage cost-rebasing delicately so as not to undermine the motivation behind such ongoing improvement efforts.

\section{Conclusion}

Payers and policymakers who aim to transform their healthcare financing systems for better cost sustainability need a comprehensive and systematic transformation plan. The atomic model described in this paper provides relevant insights and offers a structured approach to planning and implementing finance transformation in healthcare. The essence of this model lies in identifying and strengthening the core fundamentals for value-based financing models and proposing key strategies to stabilise the models for longer term sustainability. Barriers to transformation can be overcome through innovative and often extensive change management that may involve elements beyond the conventional health payer-provider-patient complex such as policy reviews, gamification strategies and social sector reforms. As health systems gain more experience and learn new lessons from their ongoing transformation journeys, the model can be further refined and enhanced to guide bolder and more impactful future transformations.

\section{ACKNOWLEDGEMENTS}

The authors would like to thank colleagues from NHG Group Finance and HQ Finance, and members of the NHG Finance Transformation Workgroup for the sharing of perspectives in the work on healthcare finance transformation, which contributed to the knowledge in this subject and made it possible to conceptualize the structured model presented in this article.

\section{CONFlicts OF INTEREST Disclosure}

The authors declare no conflicts of interest.

\section{REFERENCES}

[1] Centers for Medicare \& Medicaid Services (CMS). National Health Expenditure 2017 Highlights. 2017. Available from: https://www.cms.gov/Research-Statistics-Data-and-S ystems/Statistics-Trends-and-Reports/NationalHealt
hExpendData/downloads/highlights.pdf

[2] Organisation for Economic Co-operation and Development (OECD). Healthcare costs unsustainable in advanced economies without reform. 2015. Available from: http://www. oecd.org/health/healthcarecostsunsusta 
inableinadvancedeconomieswithoutreform.htm

[3] Buttorf C, Ruder T, Bauman M. Multiple Chronic Conditions in the United States. Santa Monica, Calif.: RAND Corporation. 2017. https://doi.org/10.7249/TL221

[4] Neumann PJ, Weinstein MC. The Diffusion of New Technology: Costs and Benefits to Health Care. In: Gelijns, A.C, Halm, E.A, (eds) The Changing Economics of Medical Technology. 1st ed. Washington D.C.: National Academy Press; 1991. 21-35 p.

[5] Clemens M. Technology and Rising Health Care Costs. Forbes. 2017. Available from: https://www.forbes.com/sites/forbestec hcouncil/2017/10/26/technology-and-rising-health-c are-costs/\#35fa2e2c766b

[6] Chamie J. Replacement Fertility Declines Worldwide. YaleGlobal Online. 2018. Available from: https://yaleglobal.yale.edu/ content/replacement-fertility-declines-worldwide

[7] Kahn J. Sin Taxes as a Mechanism of Health Care Finance. In: Humber J.M., Almeder R.F. (eds). Allocating Health Care Resources. Biomedical Ethics Reviews. Humana Press, Totowa, NJ. 1995. https://doi.org/10.1007/978-1-59259-447-4_7

[8] Doetinchem O. Hypothecation of tax revenue for health. World Health Report. Background Paper 51. Geneva, WHO. 2010. PMid:20440626. Available from: https://www. who.int/healthsystems/topics/finan cing/healthreport/51Hypothecation.pdf

[9] Porter ME. What is Value in Health Care? NEJM. 2010; 363(26): 2477-81. PMid:21142528. https://doi.org/10.1056/NEJMp1 011024

[10] Heath S. How Do Healthcare Consumers Define Value in PatientCentered Care? Patient Engagement Hit. 2019. Available from: https://patientengagementhit.com/news/how-do-healt hcare-consumers-define-value-in-patient-centered-c are

[11] Mattei P, Mitra M, Vrangbæk K, et al. Reshaping public accountability: Hospital reforms in Germany, Norway and Denmark. International Review of Administrative Studies. 2013; 79(02): 249-70. https://doi.org/10.1177/0020852313477765

[12] The King's Fund. Governance of new care models: approaches being taken in the vanguards. 2018. Available from https://www.kingsfund.org.uk/projects/supporting-n ew-nhs-care-models/emerging-innovations-vanguards

[13] World Health Organization (WHO), Regional Office for Europe. Integrated care models: an overview. 2016. Available from: http://www.euro.who.int/_data/assets/pdf_file 10005/322475/Integrated-care-models-overview.pdf

[14] Briggs A, Alderwick H, Shortell S, et al. What Can the U.S and England Learn from Each Other's Health Care Reforms? The Commonwealth Fund. 2018. Available from: https: //www. commonwealthf und.org/blog/2018/what-can-us-a nd-england-learn-each-others-health-care-reforms

[15] McClellan M, Kent J, Beales SJ, et al. Accountable Care Around The World: A Framework To Guide Reform Strategies. Health Affairs. 2014; 33(9): 1507-15. PMid:25201654. https://doi.org/10.1 $377 /$ hlthaff.2014.0373

[16] Burton DA. Accountable Care Transformation Framework. Health Catalyst. 2017. Available from: http: //www.healthcatalyst. com/wp-content/uploads/201 4/11/ACTF-Digital-2014-11-12a.pdf

[17] Miller HD. From Volume to Value: Better Ways to Pay for Health Care. Health Affairs. 2009; 28(5): 1418-28. PMid:19738259. https : //doi.org/10.1377/hlthaff.28.5.1418

[18] Medical Economics. Understanding new payment models. 2013. Available from: http://www.medicaleconomics.com/moder n-medicine-feature-articles/understanding-new-pay ment-models

[19] Kinsey A. Advantages \& Disadvantages of Capitation Payments. Bizfluent. 2018. Available from: https://bizfluent.com/info-12185015-advantage s-disadvantages-capitation-payments.html

[20] Goodson JD, Bierman AS, Fein O, et al. The Future of Capitation. The Physician Role in Managing Change in Practice. JGIM. 2001; 16: 250-6. PMid:11318926. https : //doi.org/10.1046/j. 1525 $-1497.2001 .016004250 . x$

[21] The King's Fund. Contractual models for commissioning integrated care. 2019. Available from: https://www.kingsfund.org.uk/p ublications/commissioning-contracting-integrated-c are/summary\#prime-provider-model

[22] Toward Accountable Care Consortium (TACC). The Accountable Care Guide. North Carolina: Smith, Anderson, Blount, Dorsett, Mitchell \& Jernigan, L.L.P., 2012: 12-13. Available from: http://www.tac-consortium.org/wp-content/uploa ds/2013/04/Physician_ACO_Toolkit_NC.pdf

[23] World Health Organization (WHO), Geneva. Tax-based Financing for Health Systems: Options and Experiences. Discussion Paper 4 2004. Available from: https ://www.who.int/health_financi ng/taxed_based_financing_dp_04_4.pdf

[24] Globerman S. Select Cost Sharing in Universal Health Care Countries. Fraser Institute. 2016. Available from: https://www. fraserinstitute.org/sites/default/files/select-cos t-sharing-in-universal-health-care-countries.pdf

[25] Central Provident Fund Board (CPFB). Medisave. 2019. Available from: https://www.cpf.gov.sg/Members/Schemes/schemes /healthcare/medisave

[26] Brook RH, Keeler EB, Lohr KN, et al. The Health Insurance Experiment. A Classic RAND Study Speaks to the Current Health Care Reform Debate. Santa Monica: RAND Corporation. 2006. Available from: https ://www.rand.org/pubs/research_briefs/RB91 74.html

[27] Swartz K. Cost-sharing: Effects on spending and outcomes. The Synthesis Project. Research Synthesis Report No. 20 Robert Wood Johnson Foundation. 2010. Available from: https : //www.rwjf .org/content/dam/farm/reports/issu e_briefs/2010/rwjf402103/subassets/rwjf402103_1

[28] Bicheno S. Cloud storage bundles improve stickiness but not revenues - research. Telecoms.com. 2015. Available from: http://telecoms.com/411842/cloud-storage-bundles-i mprove-stickiness-but-not-revenues-research/

[29] Maciosek MV, LaFrance AB, Dehmer SP, et al. Updated Priorities Among Effective Clinical Preventive Services. Ann Fam Med. 2017; 15(1): 14-22. PMid:28376457. https ://doi.org/10.1370/afm . 2017

[30] Stronks K, van de Mheen HD, Mackenbach JP. A higher prevalence of health problems in low income groups: does it reflect relative deprivation? J Epidemiol Community Health. 1998; 52: 548-57. PMid:10320855. https://doi.org/10.1136/jech.52.9.548

[31] Woolf SH, Aron L, Dubay L, et al. How are income and wealth linked to health and longevity? Urban Institute and Virginia Commonwealth University. 2015. Available from: https://www.urban.org/sites/default/files/publicat ion/49116/2000178-How-are-Income-and-Wealth-Linke d-to-Health-and-Longevity.pdf

[32] Tarone RE, Chu KC, Gaudette LA. Birth Cohort and Calendar Period Trends in Breast Cancer Mortality in the United States and Canada. Journal of the National Cancer Institute. 1997; 89(3): 251-6. PMid:9017006. https://doi.org/10.1093/jnci/89.3.251 
[33] Kwon JW, Song YM, Park HS, et al. Effects of age, time period, and birth cohort on the prevalence of diabetes and obesity in Korean men. Diabetes Care. 2008; 31(2): 255-60. PMid:17977938. https://doi.org/10.2337/dc07-0531

[34] Cohen JT, Neumann PJ. The cost-savings and cost-effectiveness of clinical preventive care. The Synthesis Project. Research Synthesis Report No. 18. Robert Wood Johnson Foundation. 2009. Available from: https://www.rwjf.org/content/dam/farm/reports/ issue_briefs/2009/rwjf46045/subassets/rwjf46045_1

[35] Puts MTE, Toubasi S, Andrew MK, et al. Interventions to prevent or reduce the level of frailty in community-dwelling older adults: a scoping review of the literature and international policies. Age and Aging. 2017; 46: 383-92. https : //doi .org/10.1093/ageing/afw247

[36] Looman WM, Huijsman R, Fabbricotti IN. The (cost)-effectiveness of preventive, integrated care for community-dwelling frail older people: A systematic review. Health Soc Care Community. 2019; 27: 1-30. PMid:29667259. https://doi .org/10.1111/hsc. 12571

[37] Davidson GB, Penrod JD, Kane RA, et al. Modeling the costs of case management in long-term care. Health Care Financ Rev. 1991; 13(1): 73-81. PMid:10114936.

[38] Diederich F, Konig HH, Mietzner C, et al. Costs of informal nursing care for patients with neurologic disorders: A systematic review. Neurology. 2018; 90(1): 28-34. PMid:29196573. https: //doi.org/10.1212/WNL.0000000000004763

[39] Jakobsen M, Poulsen PB, Reiche T, et al. Costs of Informal Care for People Suffering from Dementia: Evidence from a Danish Survey. Dement Geriatr Cogn Disord Extra. 2011; 1: 418-28. PMid:22187549. https://doi.org/10.1159/000333812

[40] Escribano-Sotos F, Pardo-Garcia I. Analyzing the Costs of Informal Care for Persons with Dementia in Spain. Journal of Promotion Management. 2015; 21(4): 459-74. https ://doi .org/10.1080/1049 6491.2015 .1051398

[41] Mogyorosy Z, Smith P. The main methodological issues in costing health care services: A literature review. Centre for Heath Economics, The University of York. 2005. Available from: https://www.york.ac.uk/media/che/documents/papers/ researchpapers/rp7_Methodological_issues_in_costin g_health_care_services.pdf

[42] Gold MR, Siegel JE, Russell LB, et al. Cost-effectiveness in Health and Medicine. New York: Oxford University Press; 1996.

[43] Xu X, Nardini HKG, Ruger JP. Micro-costing studies in the health and medical literature: protocol for a systematic review. Systematic Reviews. 2014 3: 47. PMid:24887208. https ://doi .org/10.118 6/2046-4053-3-47

[44] Walters SJ, Stern C, Robertson-Malt S. The measurement of collaboration within healthcare settings: a systematic review of measurement properties of instruments. JBI Database System Rev Implement Rep. 2016; 14(4): 138-97. PMid:27532315. https://doi .org/10.111 24/JBISRIR-2016-2159

[45] Jacob J, Boshoff K, Stanley R, et al. Interprofessional collaboration within teams comprised of health and other professionals: a systematic review of measurement tools and their psychometric properties. Internet Journal of Allied Health Sciences and Practice. 2017; 15(2). Available from: https://pdfs.semanticscholar.org/0caf/ 6627576316826834c45d73643a17480d8fa1.pdf

[46] European Patients Forum. Empowered patients an asset to society. In: European Patients Forum Conference Report, Brussels. 2015. Available from: http://www.eu-patient.eu/globalassets/cam paign-patient-empowerment/pe-conference-report.pdf

[47] Freeman G, Shepperd S, Robinson I, et al. Continuity of Care. Report of a Scoping Exercise for the NCCSDO. London: National Co-ordinating Centre for NHS Service Delivery and Organisation R\&D. 2000; 4-5. PMid:11202381. Available from: http://www.netscc.ac.uk/hsdr/files/project/SD O_ES_08-1009-002_V01.pdf

[48] Au Yong H. Cybersecurity needs a nuanced approach. Global-isAsian. 2017. Available from: https://1kyspp.nus.edu.sg/gi a/article/cyber-security-needs-a-nuanced-approach

[49] Arora J. What India can learn from the Japan Internet separation mandate? ET tech. 2018. Available from: https://tech.economictimes.indiatimes.com/news /corporate/what-india-can-learn-from-the-japan-int ernet-separation-mandate/63407589

[50] Australian Cyber Security Centre. Implementing Network Segmentation and Segregation. 2019. Available from: https://acsc.gov.au/publications/protect/netwo rk_segmentation_segregation.htm

[51] van Dijk W, Faber MJ, Tanke MAC, et al. Medicalisation and Overdiagnosis: What Society Does to Medicine. Int J Health Policy Manag. 2016; 5(11): 619-22. PMid:27801356. https ://doi .org/ 10.15171/ijhpm.2016.121

[52] Prince M. "If you can't measure it, you can't manage it" - essential truth, or costly myth? World Psychiatry. 2018; 17(1): 1-2 PMid:29352552. https://doi.org/10.1002/wps . 20477

[53] Mannion R, Davies HTO. Pay for performance in health care. BMJ. 2008; 336(7639): 306-8. PMid:18258966. https ://doi .org/10 $.1136 / \mathrm{bmj} .39463 .454815 .94$

[54] Eijkenaar F, Emmert M, Scheppach M, et al. Effects of pay for performance in health care: a systematic review of systematic reviews. Health Policy. 2013; 110(2-3): 115-30. PMid:23380190. https://doi.org/10.1016/j.healthpol.2013.01.008

[55] Vainieri M, Lungu DA, Nuti S. Insights on the effectiveness of reward schemes from 10-year longitudinal case studies in 2 Italian regions. Int J Health Plann Manage. 2018; 33(2): e474-84. PMid:29380905. https://doi.org/10.1002/hpm.2496

[56] Centers for Medicare \& Medicaid (CMS). Bundled Payments for Care Improvement (BPCI) Initiative: General Information. 2018. Available from: https://innovation.cms.gov/initiatives /bundled-payments

[57] Anoushiravani AA, Nunley RM. Gainsharing Strategies, Physician Champions, Getting Physician Buy In. The Journal of Arthroplasty. 2017; 32: 1723-27. PMid:28366318. https://doi.org/10.101 6/j.arth.2017.02.011

[58] Kristensen SR, Bech M, Lauridsen JT. Who to pay for performance? The choice of organisational level for hospital performance incentives. Eur J Health Econ. 2016; 17(4): 435-42. PMid:25860814. https://doi.org/10.1007/s10198-015-0690-0

[59] Engstrom SM, Nunley RM. Gain sharing in bundled payment TJA: Is it the way forward? Seminars in Arthroplasty. 2018; 29: 3-6. https://doi.org/10.1053/j.sart.2018.04.007

[60] Rana AJ, Bozic KJ. Bundled Payments in Orthopaedics. Clin Orthop Relat Res. 2015; 473(2): 422-5. PMid:24554458. https: //doi.org/10.1007/s11999-014-3520-2

[61] Managed Care Executive. Seven risk-sharing mistakes to avoid in healthcare. Modern Medicine Network. 2016. Available from: https://www . managedhealthcareexecutive.com/hospita ls/seven-risk-sharing-mistakes-avoid-healthcare

[62] Lemstra M, Mackenbach J, Neudorf C, et al. High health care utilization and costs associated with lower socio-economic status: results from a linked dataset. Can J Public Health. 2009; 100(3): 180-3. PMid: 19507718.

[63] Alderwick H, Ham C, Buck D. Population health systems. Going beyond integrated care. The King's Fund. 2015. Available from: https://www.kingsfund.org.uk/sites/default/files/f 
ield/field_publication_file/population-health-sys tems-kingsfund-feb15.pdf

[64] Dickinson H, Glasby J. "Why Partnership Working Doesn't Work" Pitfalls, problems and possibilities in English health and social care. Public Management Review. 2010; 12(6): 811-28. https: //doi.org/10.1080/14719037.2010.488861

[65] Cameron A, Lart R, Bostock L, et al. Factors that promote and hinder joint and integrated working between health and social care services: a review of research literature. Health Soc Care Community. 2014; 22(3): 225-33. PMid:23750908. https://doi.org/10.1111/hs c. 12057

[66] Mason A, Goddard M, Weatherly H, et al. Integrating funds for health and social care: an evidence review. Journal of Health Services Research \& Policy. 2015; 20(3): 177-88. PMid:25595287. https://doi .org/10.1177/1355819614566832

[67] Leutz WN. Five Laws for Integrating Medical and Social Services: Lessons from the United States and the United Kingdom. The Milbank Quarterly. 1999; 77(1): 77-110. PMid:10197028. https://doi.org/10.1111/1468-0009.00125

[68] Himmelstein DU, Jun M, Busse R, et al. A comparison of hospital administrative costs in eight nations: US costs exceed all others by far. Health Aff (Millwood). 2014; 33(9): 1586-94. PMid:25201663. https://doi.org/10.1377/hlthaff .2013.1327

[69] Jiwani A, Himmelstein D, Woolhandler S, et al. Billing and insurancerelated administrative costs in United States' health care: synthesis of micro-costing evidence. BMC Health Serv Res. 2014; 14 : 556. PMid:25540104. https ://doi.org/10.1186/s12913-014 -0556-7

[70] Tseng P, Kaplan RS, Richman BD, et al. Administrative Costs Associated With Physician Billing and Insurance-Related Activities at an Academic Health Care System. JAMA. 2018; 319(7): 691-7. PMid:29466590. https ://doi.org/10.1001/jama.2017.1914 8

[71] Royse D. Better billing? Healthcare can learn from other industries. Modern Healthcare. 2017, Apr 28. Available from: https://www.modernhealthcare.com/article/20170428/ TRANSFORMATIONO2/170429920

[72] Papperman R. Transforming Medical Bills into a Competitive Advantage. For the Record. 2019. Available from: https://www.fo rtherecordmag.com/news/063015_exclusive.shtml

[73] Anderson S. BillingTree's New Healthcare Study Finds Mobile Payments On The Rise. Paymentweek, 2018, Feb 28. Available from: https://paymentweek.com/2018-2-28-billingtree s-new-healthcare-study-finds-mobile-payments-rise

[74] The Health Finance \& Governance Project. Mobile Money for Health. Bethesda. 2013. Available from: https://www.hfgproject.org/wp-content/uploads/2 013/12/Mobile-Money-for-Health-Case-Study.pdf
[75] Tode C. Mobile payment data breaches to grow in the next 12 months: report. RETAILDIVE, 2019. Available from: https : //www.reta ildive.com/ex/mobilecommercedaily/mobile-payment-d ata-breaches-to-grow-in-the-next-12-months-report

[76] Barnes AJ, Unruh L, Chukmaitov A, et al. Accountable care organizations in the USA: Types, developments and challenges. Health Policy. 2014; 118: 1-7. PMid:25145942. https ://doi .org/10.1 016/j.healthpol.2014.07.019

[77] World Health Organization (WHO). Decentralisation. 2004. Available from: https://www. who.int/health-laws/topics/gov ernance-decentralisation/en

[78] Vrangbæk K. Towards a typology for decentralization in health care. In: Saltman, R.B., Bankauskaite, V., Vrangbæk, K., ed., Decentralization in Health Care. 1st ed. Berkshire, England: McGraw Hill; 2007. 44-62 p. PMid:18634659.

[79] Brinkerhoff DW. Accountability and health systems: toward conceptual clarity and policy relevance. Health Policy and Planning. 2004; 19(6): 371-9. PMid:15459162. https ://doi.org/10.1093/heap ol/czh052

[80] Sharma B, Agrawal M. Factors Affecting Adherence to Healthy Lifestyle. Int J Pure App Biosci. 2017; 5(4): 105-116. https: //doi.org/10.18782/2320-7051.5342

[81] Chou YK. Octalysis - the complete Gamification framework. 2015. Available from: https://yukaichou.com/gamification-exa mples/octalysis-complete-gamification-framework

[82] Cugelman B. Gamification: What It Is and Why It Matters to Digital Health Behaviour Change Developers. JMIR Serious Games. 2013; 1(1): e3. PMid:25658754. https ://doi.org/10.2196/ga mes. 3139

[83] Johnson D, Deterding S, Kuhn K, et al. Gamification for health and well-being: A systematic review of the literature. Internet Interv. 2016; 6: 89-106. PMid:30135818. https://doi.org/10.1016/ j.invent.2016.10.002

[84] Sailer M, Hense JU, Mayr SK, et al. How gamification motivates: An experimental study of the effects of specific game design elements on psychological need satisfaction. Computers in Human Behavior. 2017; 69: 371-80. https ://doi.org/10.1016/j . chb.2016.12. 033

[85] Public Administration Select Committee. Public Services and the Third Sector: Rhetoric and Reality. Eleventh Report of Session 2007-2008, UK. House of Commons. 2008: 118-119. Available from: https://publications.parliament.uk/pa/cm200708 /cmselect/cmpubadm/112/112ii.pdf

[86] Mathi B, Mohamed S. Unmet Social Needs in Singapore. Lien Centre for Social Innovation. 2011; 35-41. Available from: https://lcsi.smu.edu.sg/sites/lcsi.smu.edu.sg/ files/Unmet_Social_Needs_in_Singapore.pdf 